\title{
Aquatic habitat use by amphibians with specific reference to Rana temporaria at high elevations (Retezat Mountains National Park, Romania)
}

\author{
Dan Cogălniceanu ${ }^{1}$, Raluca Băncilă ${ }^{1,2 *}$, Rodica Plăiaşu ${ }^{1,2}$, Ciprian Samoilă ${ }^{1}$ and Tibor Hartel ${ }^{1,3}$ \\ ${ }^{1}$ University Ovidius Constanţa, Faculty of Natural Sciences, Aleea Universităţii, No. 1, 900470, Constanţa, Romania \\ 2 "Emil Racoviţă" Institute of Speleology of the Romanian Academy, 13 Septembrie Road, No. 13, 050711, Bucharest, Romania \\ 3 Institute of Ecology, Faculty of Sustainability, Leuphana University Lüneburg, 21335, Lüneburg, Germany
}

Received 26 March 2012; Accepted 18 August 2012

\begin{abstract}
Alpine areas are extreme habitats that require special adaptations and involve major trade-offs in terms of life history. Amphibians have the ability to adapt both their life history and developmental traits to alpine environments. Temperate amphibians depend on the quality and availability of aquatic habitats for reproduction. We explored the aquatic habitat used by amphibians in the alpine area of Retezat Mountains, Southern Carpathians, Romania. We surveyed 40 aquatic habitats in a 380 ha area delimited by mountain crests and drained by a steep valley. Each aquatic habitat was characterized using 10 environmental variables. Only three amphibian species occur at elevations above $1900 \mathrm{~m}$, the most widespread being the Common Frog Rana temporaria. The Common Frog showed preference for breeding aquatic habitats, the variables of importance being altitude, solar radiation, water chemistry and grazing. Higher elevation and lower solar radiation decreased frog occurrence, while the impact of grazing favored the use of water bodies. Acidification is eminent in the area with $\mathrm{pH}$ dropping below 5 in $20 \%$ of the water bodies. Overall, amphibian occurrence in alpine area can be partly explained by the characteristics of aquatic habitats.
\end{abstract}

Key words: Alpine / Rana temporaria / Carpathian Mountains / reproduction / habitat use

\section{Introduction}

Temperate amphibians not only depend on the quality and availability of aquatic habitats for reproduction but also depend on suitable surrounding terrestrial areas to complete their year round life history (Van Buskirk, 2005). They are ectotherm vertebrates with permeable skin that serves many physiological functions, at the same time making them sensitive to variation in microclimatic conditions and pollution. Alpine areas are extreme habitats that require special adaptations and involve major tradeoffs in terms of life history (Miaud and Merilä, 2001). Amphibians can adapt their life history and developmental traits to alpine environment by energy allocation in offsprings (Miaud et al., 1999; Miaud and Merilä, 2001), age structure (Miaud et al., 1999, 2000), movement activity and population structure (Veith et al., 2002; Funk et al., 2005), breeding activity (Elmberg and Lundberg, 1991), morphology and development (Denoël and Joly, 2000; Merilä et al., 2000), mating strategies (Vieites et al., 2004)

\footnotetext{
*Corresponding author: raluca .bancila@iser.ro
}

and competitive ability of larvae (Lindgren and Laurila, 2010).

Alpine lakes are good model systems for addressing large-scale effects of human activities because (i) they are relatively simple systems with few species and less complex food webs than lowland lakes, (ii) they respond rapidly to environmental changes including climate and atmospheric deposition and (iii) direct human influences are usually low (Psenner and Schmidt, 1992; Wolfe et al., 2001; Fjellheim et al., 2009). Alpine catchments are vulnerable to anthropogenic pollution since the watersheds have limited capacity to neutralize acid deposition, except when in limestone areas, and pollutants will rapidly reach water bodies due to barren rocks, thin soils and sparse vegetation cover (e.g., Birks et al., 2004).

Studies investigating the spatial distribution of amphibians in mountainous areas of Central and Eastern Europe are still scarce (e.g., Babik and Rafiński, 2001). The alpine area above the tree-line in the Retezat National Park is relatively free of man-mediated impacts. Low intensity grazing during the summer period and tourism, which is generally restricted, represents the only direct impact. The 
alpine landscape is characterized by a diversity of stagnant water bodies (glacial lakes, ponds, bogs and mires), interconnected by a dense network of streams. Most of the fish populations that until recently inhabited the larger glacial lakes have gone extinct. Past surveys of the herpetofauna in the park revealed the presence of seven species of amphibians (Cogălniceanu et al., 2001), but only three (Rana temporaria L., Bufo bufo L. and Ichtyosaura alpestris L.) occur in the alpine area above $1700 \mathrm{~m}$ (Plăiaşu et al., 2010).

The Common Frog (R. temporaria) is the most widespread brown frog in Europe and in many areas is very common (Kuzmin et al., 2009). It also occurs in the extreme environments, such as subarctic and alpine, where often is the only amphibian species present. It reproduces in water where the tadpoles develop for several weeks until metamorphosis, after which they migrate on land and spend the rest of their life. Understanding the ecology of the habitat use of this amphibian in extreme conditions will provide important insights for management and conservation measures, when considering alterations induced by climate change. In the present study, we focused on identifying the relevant environmental predictors of aquatic habitats used for reproduction by the Common Frog (R. temporaria) in an alpine area, based on the hypothesis that frogs are selective in their choice for breeding habitats.

\section{Materials and methods}

\section{Study area}

The Retezat National Park (RNP), located in the Southern Carpathians, was established in 1935. In 1979, RNP was included in the international network of Biosphere Reserves (MAB/UNESCO). It covers an area of over 38000 ha, out of which 1630 ha is a strictly protected area. In the lower parts of the park, there are deep and narrow valleys, while the higher parts consist of glacial plateaus. The main geology is represented by Danubian metamorphic rocks dominated by slightly metamorphosed crystalline schists; the glacial relief allowed lakes to form in the deeper parts of the moraines (Schreiber and Sorocovschi, 1992). The run-offs vary with altitude, from $14.3 \mathrm{~L} . \mathrm{s}^{-1} \cdot \mathrm{km}^{-2}$ between 600 and $800 \mathrm{~m}$ to $28 \mathrm{~L} . \mathrm{s}^{-1} \cdot \mathrm{km}^{-2}$ between 1600 and $1800 \mathrm{~m}$ and up to 36.6 L.s ${ }^{-1} \cdot \mathrm{km}^{-2}$ at altitudes higher than $2200 \mathrm{~m}$ (Schreiber and Sorocovschi, 1992). The climate is moderately cold and humid, with yearly average temperatures between $6{ }^{\circ} \mathrm{C}$ in the valleys and $-2{ }^{\circ} \mathrm{C}$ in the alpine areas. Annual rainfall varies between 900 and $1300 \mathrm{~mm}$ (Fărcaş and Sorocovschi, 1992). The overall pattern of the surface distribution according to altitude in the Retezat Mountains is distinct, with more than half of the area above $1600 \mathrm{~m}$ (Urdea, 2000). The steep mountain sides do not provide aquatic habitats for amphibians and isolate the populations from high and low altitudes.
In the Retezat Mountains, there are about 100 alpine lakes, of which 58 are permanent (Pişotă, 1971). The conductivity of the water is very low and the $\mathrm{pH}$ is slightly acidic (Straskrabova et al., 2006). Fish were historically known from seven lakes, and starting in the 1960s another 28 lakes were stocked with fish (Decei, 1981). Introductions were carried out both with native (Salmo trutta lacustris L. and Phoxinus phoxinus L.) and non-native species (Salvelinus fontinalis Mitchill, Coregonus peled Gmelin and Oncorhynchus mykiss Walbaum) (Decei, 1981). Fish have gone extinct from at least eight lakes previously stocked with non-native species. None of the three lakes from the study area previously stocked with fish holds amphibians. In the area studied by us only the deepest lake (Zănoaga) still holds fish, but is still a breeding habitat for the Common Toad (B. bufo).

This study was conducted in the Judele glacial valley, on a 380 ha area. It is bordered by four large glacial lakes (Judele, Ascuns, Răsucit and Zănoaga) (Fig. 1). The area is well delimited by high mountain crests and is funneled into a steep forested river basin that drains the entire zone. The area investigated is rather uniform, with patches of dwarf pine interspersed with grassland and scree, shaped by the dense hydrological network. There is a steep altitudinal gradient, with the proportion of dwarf pine decreasing and scree increasing with elevation.

\section{Amphibian inventory}

The present study was performed during three consecutive years from 2004 to 2006. Two visits were made each year: one in June and one in early September, by a team of three persons, for five days fieldwork in the area. In 2004, the site was visited only in autumn. Each water body was visited at least once a year in autumn and sampled for 15-45 min depending on size, depth, presence and/or density of amphibians and weather conditions. In June not all water bodies were ice-free, so no consistent observations could be made.

Amphibians were surveyed using diurnal visual transects and active search for adults and metamorphs along the entire shore, and visual search or netting for larvae in the water (Cogălniceanu et al., 2006). The presence of larvae in the water and/or fresh metamorphs around the banks was an indication of successful reproduction. The high water transparency (total transparency for all aquatic habitats, except the deepest lake - Zănoaga) coupled with the scarcity of submerged and riparian vegetation and submerged logs allowed for easy identification of larvae and adults.

\section{Inventory of water bodies}

We inventoried all permanent lakes and most of the temporary ponds (hereafter water bodies) in the study area, except for ephemeral (i.e., $<5 \mathrm{~cm}$ deep) ones. The total number of water bodies included in the study was 40 . 


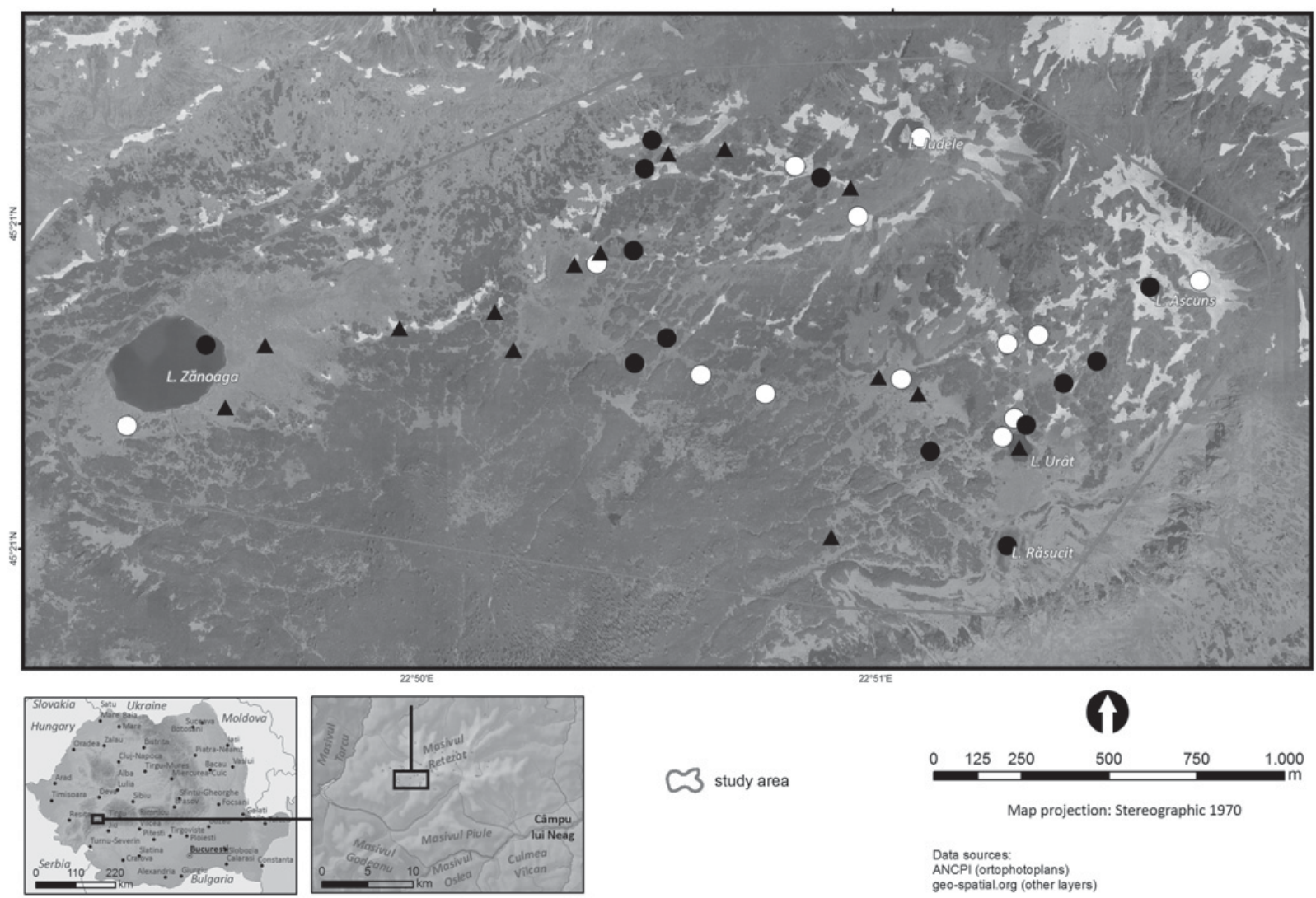

Fig. 1. The map of surveyed water bodies (main box) showing the extent to Romania (bottom left box) and Retezat Mountains (bottom middle box). White circles are symbols for water bodies where no life stage was present, black circles where only adults were present and black triangles for water bodies where larvae and/or juveniles were present.

Water bodies were characterized by a number of variables: water body location ( $x$ and $y$ geographic coor dinates), elevation $(\mathrm{m})$, solar radiation $\left(\mathrm{W} \cdot \mathrm{h} / \mathrm{m}^{2}\right)$, habitat type (permanent and temporary), surface $\left(\mathrm{m}^{2}\right)$, maximum water depth $(\mathrm{cm}), \mathrm{pH}$, conductivity $(\mu \mathrm{S} / \mathrm{cm})$ and the presence of fish and/or invertebrate predators (Coleoptera, Hemiptera or Odonata) (absent or present). The presence/absence of fish was based on visual assessments done during the period 2000-2008 from the bank. The presence of invertebrate predators was assessed visually and by dip-netting. The degree of isolation of each water body was estimated from the average distance of the focal water body to the nearest three water bodies (m). We quantified the only man-mediated impact in the area, i.e., grazing, as present or absent. Grazing (mostly sheep and rarely horses) occurs for about 3 months during the summer.

Geographic coordinates and elevation were recorded with a handheld Garmin GPS device. Water $\mathrm{pH}$ and conductivity were measured with a portable Oakton Waterproof $\mathrm{pH} / \mathrm{mV} / \mathrm{C}$ Meter after calibration. Morphometric data for the large glacial lakes were taken from Pişotă (1971). Morphometric parameters such as slope and orientation were derived from SRTM $90 \mathrm{~m}$ Digital Elevation Data (Jarvis et al., 2008) in ArcGIS Desktop 9.3.1 using Spatial Analyst Tools (ESRI, 2009a). Both slope and aspect raster data values were used to calculate the degree of insolation. The point solar radiation analysis tool (ESRI, 2009b) was used to calculate the amount of radiant energy for each sampling site based on methods from the hemispherical view shed algorithm (Fu and Rich, 2002). Solar radiation calculations were performed for the period 1 August-1 October in each year (2004-2006), and an average value was computed.

\section{Data analysis}

Prior to analysis all continuous variables were $z$ transformed (standardized to an average of zero and a standard deviation of one) in order to increase comparability of the variables effects (Ćirović et al., 2008). We classified each aquatic habitat into three groups: (1) only adults were present (i.e., suitable as habitat but not used for breeding); (2) larvae and metamorphs were present (i.e., suitable for breeding); (3) neither larvae, metamorphs nor adults were present (i.e., unsuitable). A discriminant function analysis (DFA) was run to explore the multivariate differences among the three groups. We further classified the aquatic habitats into "reproductive sites" (sites where larvae and metamorphs were present) and "non-reproductive sites" (sites where no life stage or only adults were present). 
Table 1. The candidate models designed to analyze Rana temporaria habitat use for breeding.

\begin{tabular}{llll}
\hline & \multicolumn{1}{c}{ Model name } & Covariate & \multicolumn{1}{c}{ Explanation } \\
\hline 1 & Regional climatic model & Alt, Sr & Altitude and solar radiation important \\
2 & Water volume model & $\mathrm{D}, \mathrm{S}$ & Maximum water depth and pond surface important \\
3 & Pond permanence model & $\mathrm{Ht}, \mathrm{D}, \mathrm{S}$ & Habitat type, maximum water depth and pond surface important \\
4 & Water chemistry model & $\mathrm{pH}, \mathrm{C}$ & $\mathrm{pH}$ and conductivity important \\
5 & Predation model & $\mathrm{Pr}$ & Fish and/or invertebrate predators presence important \\
6 & Isolation model & $\mathrm{Adl}$ & Degree of isolation important \\
7 & Man-mediated impact & $\mathrm{Gr}$ & Grazing important \\
\hline
\end{tabular}

Alt, altitude; Sr, solar radiation; Ht, habitat type; D, maximum water depth; S, surface; C, conductivity; Pr, presence of fish and/or invertebrate predators; Adl, average distance between three closest ponds; Gr, grazing.

Table 2. The characteristics of water bodies from Judele Valley, the Retezat National Park $(n=40)$, expressed as mean values with standard deviation and below the range (min-max). Water $\mathrm{pH}$ and conductivity values are based on multiple measurements done during the study.

\begin{tabular}{lcr}
\hline Parameter & Permanent $(N=26)$ & Temporary $(N=14)$ \\
\hline Area $\left(\mathrm{m}^{2}\right)$ & $5852.9 \pm 12234(58-47100)$ & $298.6 \pm 353.6(27.7-1100)$ \\
Maximum depth $(\mathrm{cm})$ & $221.5 \pm 635.7(20-2900)$ & $32.7 \pm 19.2(5-75)$ \\
Altitude $(\mathrm{m})$ & $2081.8 \pm 62.6(1972-2202)$ & $2086.8 \pm 69.2(2007-2195)$ \\
$\mathrm{pH}$ & $6.7(4.5-8.1)$ & $5.6(4.7-6.4)$ \\
Conductivity $(\mu \mathrm{S} / \mathrm{cm})$ & $11.2 \pm 2.1(7.2-15.6)$ & $11.4 \pm 5.5(4.5-25.5)$ \\
\hline
\end{tabular}

Generalized linear models (GLMs) were used to relate the explanatory variables to $R$. temporaria habitat used for breeding. A binomial error distribution (logit regression) was assumed to relate the binary response variable $(1=$ reproductive sites; $0=$ non-reproductive sites $)$ and explanatory variables. We designed a set of seven biologically reasonable models (Table 1) and selected the best approximating model using the Akaike's Information Criterion corrected for small samples sizes (AICc) (Burnham and Anderson, 2002). Three predictors' models were considered the most complex models based on the minimum sample size required for multiple regressions (http://www.danielsoper.com/statcalc/calc01.aspx). To avoid multi-collinearity, for models including several variables, Spearman's rank correlation coefficient was used to check the correlation between pairs of the transformed variables. The models were ranked according to their AICc values, the best model having the smallest AICc value. Delta $(\Delta)$ AICc was computed as the difference between each model and the best model. The Akaike weights $\left(w_{i}\right)$ express the weight of evidence favoring the model as the best of all models. Statistical procedures were implemented in R 2.1.0 (R Development Core team, 2009). Model selection and model averaging were performed with AICcmodavg package (Mazerolle, 2009).

\section{Results}

\section{Water bodies' survey}

The water bodies were located at elevations between 1972 and $2202 \mathrm{~m}$ (mean and standard deviation: $2083 \pm 64 \mathrm{~m}$ a.s.1.) (Fig. 1): $65 \%(n=26)$ were permanent and $35 \% \quad(n=14)$ were temporary. One-fifth of the investigated water bodies had a $\mathrm{pH}$ lower than 5 . The parameters characterizing the water bodies are presented in Table 2. Fish were present in only one lake, while invertebrate predators were present in $42.5 \%$ of the water bodies $(n=17)$. The average distance between the three nearest neighbor water bodies was $198.8 \pm 97 \mathrm{~m}$.

\section{Habitat use}

Amphibians were present in $67.5 \%$ of the water bodies. R. temporaria was found in $65 \%$ of the water bodies, I. alpestris in $17.5 \%$ and B. bufo in $7.5 \%$. R. temporaria had the widest altitudinal range and reached the highest elevation $(2195 \mathrm{~m})$, while $B$. bufo reached $2021 \mathrm{~m}$ and I. alpestris $2095 \mathrm{~m}$. Amphibians reproduced in $40 \%$ of the water bodies, with half of the habitats containing two species (i.e., $R$. temporaria and one of the other two amphibian species). $R$. temporaria reproduced in 14 water bodies (34\%).

DFA generated two functions that together accounted for $100 \%$ of the variance between the three $R$. temporaria groups considered (i.e., with larvae or metamorphs, only with adults or no life stage present) (Table 3). The first function accounted for $64.1 \%$ of the variance, and was most highly correlated with solar radiation $(r=0.735)$ and with altitude $(r=-0.646)$. The second function accounted for $35.9 \%$ of the variance, and was most highly correlated with grazing $(r=0.968)$. The distribution of the water bodies according to their use was partly overlapping but still distinct among those used for reproduction (category 2), used as habitat only by adults (category 1 ) and avoided (category 3) (Fig. 2).

None of the seven GLM models could be discarded, all having a $\triangle \mathrm{AICc}<10$ (Table 4$)$. The model best supported 
Table 3. The summary statistics for the three group DFA: correlations between original variables and discriminant functions and discriminant scores for each group. (See also Figure 2.)

\begin{tabular}{lcc}
\hline Variable considered & Function 1 & Function 2 \\
\hline Eigenvalue & 0.42 & 0.23 \\
\% variance & 64.1 & 35.9 \\
R with & & \\
$\quad$ Habitat type & -0.063 & 0.227 \\
$\quad$ Surface & -0.064 & 0.364 \\
$\quad$ Maximum water depth & -0.321 & -0.096 \\
pH & -0.338 & 0.31 \\
$\quad$ Conductivity & 0.417 & 0.393 \\
$\quad$ Altitude & -0.646 & 0.254 \\
$\quad$ Solar radiation & 0.735 & 0.039 \\
$\quad$ Average distance between & 0.429 & -0.202 \\
$\quad$ three nearest ponds & 0.151 & 0.031 \\
$\quad$ Presence of fish and/or & & \\
$\quad$ invertebrate predators & -0.223 & 0.968 \\
$\quad$ Grazing & & \\
Group centroids: & -0.716 & 0.354 \\
1. Only Rana temporaria adults & & \\
$\quad$ present & 0.777 & 0.272 \\
2. Larvae and metamorphs present & -0.067 & -0.683 \\
3. No life stage present & &
\end{tabular}

by the data included solar radiation and altitude (regional climatic model). The grazing model and water chemistry model were also highly ranked $(\triangle \mathrm{AICc}<2)$ and are similarly plausible to the regional climatic model. The explained deviance of the best models ranged between 38.82 and 44.28 , indicating a generally good explanatory power for the models.

\section{Discussion}

$R$. temporaria occurrence was explained based on several variables that reflected its aquatic habitat preferences. In an alpine area, the availability of breeding habitats for amphibians is generally limited, both in structure and by elevation (Bosch and Martinez-Solano, 2003). Nevertheless two-thirds of the accessible habitats were not used by $R$. temporaria for breeding, supporting the hypothesis that frogs selected their reproduction sites and did not use them randomly. This is similar to the study of Grözinger et al. (2012) in northern Bavaria that showed that only one-third of the available ponds were used for spawning. We also found that habitat use by $R$. temporaria is influenced even by small human-related perturbations such as grazing.

The regional climatic model of our study was ranked the best, and it included altitude. This is consistent with a similar study in a mountain range in Central Spain reported that the only limiting factor to amphibian distribution appeared to be altitude (Bosch and Martinez-Solano, 2003). In our study, the density and quality (in terms of depth and area) of aquatic habitats decreased with

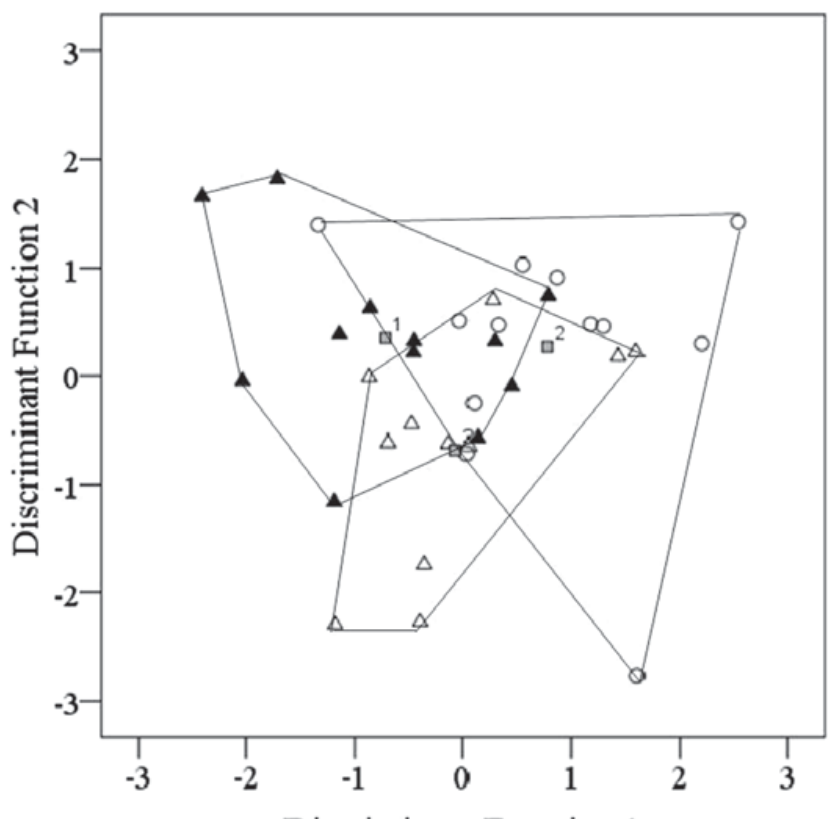

Discriminant Function 1

Fig. 2. The multivariate distribution of the water bodies in relation to their use by Rana temporaria, and the position of the centroids on the first two discriminant functions. Centroids: gray squares; water bodies where only adults were present: black triangles; water bodies where larvae and juveniles were present: open circles; water bodies where no life stage was present: white triangles.

altitude. The observed altitudinal occurrence of the three amphibians found by us is consistent with the reported highest altitudinal limits for $R$. temporaria $(2500 \mathrm{~m})$ and for B. bufo $(2160 \mathrm{~m})$ (Vences et al., 2003). High altitude populations are often experiencing mortality because of extreme climate events, and this may influence the observed occurrence patterns. $R$. temporaria is particularly exposed to winter mortality because a significant proportion of the population overwinters in water due to lack of suitable terrestrial hibernacula. For example, the winter of 2004-2005 was longer than usual, with below zero temperatures lasting for 8 months at elevations above 2000, until the beginning of June 2005. The low levels of dissolved oxygen in the water trapped below the ice (e.g., Tattersall and Ultsch, 2008) caused a mass mortality event in a $R$. temporaria population that used a shallow permanent alpine lake located at $2140 \mathrm{~m}$ for breeding and overwintering. More than 80 dead adults were observed trapped under ice by mid-June, when ice thaw allowed partial visibility in the lake (Cogălniceanu and Hartel, 2005). Coping with extreme climate events may represent an additional variable used in habitat selection, though difficult to quantify. Our results pointed to two important variables (solar radiation and altitude) that are both indicators of temperature variation.

Climate is also a forcing agent on the acid-base balance in the sensitive high-altitude lakes (Koining et al., 1998). Water chemistry, particularly acidification, appears to 
Table 4. GLM selection results. Statistics include the explained variance $\left(D^{2}\right)$, number of estimated parameters $(\mathrm{K})$, the second-order Akaike Information Criterion corrected for small sample sizes (AICc), AIC difference $(\Delta i)$ and Akaike weights (wi).

\begin{tabular}{|c|c|c|c|c|c|}
\hline Model name & $D^{2}(\%)$ & $\mathrm{AICc}$ & $\triangle \mathrm{AICc}$ & $w i$ & $K$ \\
\hline Regional climatic model & 38.82 & 45.60 & 0 & 0.36 & 3 \\
\hline Man-mediated impact & 42.53 & 46.91 & 1.31 & 0.19 & 2 \\
\hline Water chemistry model & 40.17 & 46.95 & 1.35 & 0.18 & 2 \\
\hline Predation model & 43.28 & 47.66 & 2.05 & 0.13 & 2 \\
\hline Isolation model & 44.28 & 48.66 & 3.06 & 0.08 & 2 \\
\hline Water volume model & 42.86 & 49.64 & 4.04 & 0.05 & 4 \\
\hline Pond permanence model & 42.79 & 52.13 & 6.52 & 0.01 & 3 \\
\hline
\end{tabular}

play only a minor role on amphibian global decline (Beebee and Griffiths, 2005), but low $\mathrm{pH}$ was shown to cause in $R$. temporaria a prolongation of embryogenesis, increased embryonic mortality and increased larval period, resulting in lower reproductive success (Glos et al., 2003). Retezat Mountains are being affected by acidification, with critical load exceedance recently reported for the first time (Curtis et al., 2005). The water chemistry model in our study was highly plausible and included the $\mathrm{pH}$. Thus, both low summer temperatures and $\mathrm{pH}$ delay larval development and a prolonged larval period can seriously limit the species ability to breed successfully in higher altitude water bodies. The use of temporary water bodies for breeding may be risky due to their unpredictable hydroperiod. The tadpoles of $R$. temporaria may cope with such uncertainties based on their extreme phenotypic plasticity (e.g., Loman, 1999), which is higher in alpine populations (Sommer and Pearman, 2003). Overall we expect that the predicted $\mathrm{pH}$ decline in the future will increase the number of unsuitable water bodies for reproduction. This in turn might cause a fragmentation of the present range with the loss of the patchy population structure.

The third model that ranked among the best was the man-mediated impact model, the only impact in the area being grazing. The relationship between the grazing intensity and the amphibian occurrence in ponds and lakes is still a largely unexplored topic of amphibian conservation ecology, with no studies available for high elevation areas. Although some studies claim a negative impact on amphibians (Schmutzer et al., 2008), other report a differential species-specific response (Burton et al., 2009). Low intensity grazing may contribute to the maintenance of wetlands through the removal of excessive vegetation that would otherwise adversely affect pond quality for amphibians (Pyke and Marty, 2005). We consider that moderate grazing has a two-fold beneficial impact in the study area. Most important of all it increases the food resource: for tadpoles from the input of nutrients provided by manure in the oligotrophic water bodies, and for juveniles and adults by increasing invertebrate abundance in the nearby terrestrial zone. It also maintains a low height of the vegetation cover in surrounding grasslands, thus facilitating dispersal.

The low distance between water bodies (ca. $200 \mathrm{~m}$ on average) was well within the movement distance recorded for $R$. temporaria and the other two species found by us
(Kovar et al., 2009). Nevertheless, the GLM isolation model had one of the highest deviance $(44.28 \%)$ and cannot be discarded. Given these conditions, we believe that the $R$. temporaria population studied by us has a 'patchy population' character (Harrison and Taylor, 1997). The two other species of amphibians present in the area occur together with $R$. temporaria, and their presence can thus be considered an indicator of a quality aquatic habitat for breeding.

Our study showed that the occurrence of amphibians in relatively pristine alpine areas of Eastern Europe can be partly explained by water body characteristics. A similar study conducted in a forested area in northern Bavaria (Grözinger et al., 2012) could not identify environmental variables to explain habitat selection. This was probably due to the higher complexity of the habitats studied, highlighting the importance and value of studies in less complex alpine habitats. $R$. temporaria showed selectivity in its choice of water bodies for breeding, and can also be considered a good surrogate species for assessing aquatic habitat suitability for other amphibians. Despite the high density of aquatic habitats and the widespread presence of amphibians, they persist and expand based only on several temporary and permanent aquatic habitats that act as source populations. This in turn raises an important conservation issue since water bodies have contrasting values for the persistence of amphibians. It is important to identify water bodies where reproduction was successful, since they require special attention, especially in terms of banning fish stocking and permitting moderate grazing in their vicinity. The importance of high altitude water bodies for the persistence of amphibian populations is relative due to the shifts in conditions associated with climate change. Thus, regular monitoring is required for the periodic re-evaluation of their status and conservation value.

Acknowledgements. Access in the area was granted by the Romanian Academy, Commission for Nature Conservation, while the Park Administration provided lodging. Funding was provided by CNCSIS grant $1114 / 2004$ to D.C. The research stay of TH in Germany was supported by Alexander von Humboldt Foundation. Dr Mihai Vâlcu provided helpful comments on data analysis. The manuscript benefited greatly from the comments of Dr Marc Mazerolle and two anonymous reviewers. We thank Dr Daniela Strat, Alexandru Cogălniceanu and Demeter László for help during fieldwork. 


\section{References}

Babik W. and Rafiński J., 2001. Amphibian breeding site characteristics in the Western Carpathians, Poland. Herpetol. J., 11, 41-51.

Beebee T.J.C. and Griffiths R.A., 2005. The amphibian decline crisis: a watershed for conservation biology? Biol. Conserv., $25,271-285$.

Birks H.J.B., Jones V.J. and Rose N.L., 2004. Recent environmental change and atmospheric contamination on Svalbard as recorded in lake sediments - synthesis and general conclusions. J. Paleolimnol., 31, 531-546.

Bosch J. and Martinez-Solano I., 2003. Factors influencing occupancy of breeding ponds in a montane amphibian assemblage. J. Herpetol., 37, 410-413.

Burnham K.P. and Anderson D.R., 2002. Model Selection and Multimodel Inference: a Practical Information-theoretic Approach (2nd edn.), Springer-Verlag, New York, 485 p.

Burton E.C., Gray M.J., Schmutzer A.C. and Miller D.L., 2009. Differential responses of postmetamorphic amphibians to cattle grazing in wetlands. J. Wildlife Manage., 73, 269-277.

Ćirović R., Vukov T.D., Radović D., Džukić G. and Kalezić M.L., 2008. Distribution patterns and environmental determinants of European newts in the Montenegrin karst area. Biologia, 63, 745-752.

Cogălniceanu D. and Hartel T., 2005. Frost induced mortality in a high altitude population of Rana temporaria. Froglog, 72, 3-4.

Cogălniceanu D., Ghira I. and Ardeleanu A., 2001. Spatial distribution of herpetofauna in the Retezat Mountains National Park, Romania. Biota, 2, 9-16.

Cogălniceanu D., Hartel T. and Plăiaşu R., 2006. Establishing an amphibian monitoring program in two protected area of Romania. In: Vences M., Köhler J., Ziegler T. and Böhme W. (eds.), Herpetologia Bonnensis II, Proceedings of the 13th Congress of the Societas Europea Herpetologica. SEH, Bonn, 31-34.

Curtis C., Botev I., Camarero L., Catalan J., Cogălniceanu D., Hughes M., Kernan M., Kopacek J., Korhola A., Mosello R., Psenner R., Stuchlik E., Veronesi M. and Wright R., 2005. Acidification in European mountain lake districts: a regional assessment of critical load exceedance. Aquat. Sci., 67, 237-251.

Decei P., 1981. Lacuri de munte. Drumeţie şi pescuit. [Mountain Lakes. Trekking and Fishing]. Editura Sport-Turism, Bucharest, Romania.

Denoël M. and Joly P., 2000. Neoteny and progenesis as two heterochronic processes involved in paedomorphosis in Triturus alpestris (Amphibia, Caudata). Proc. R. Soc. Lond. $B, 267,1481-1485$.

Elmberg J. and Lundberg P., 1991. Intraspecific variation in calling, time allocation and energy reserves in breeding male common frogs Rana temporaria. Ann. Zool. Fenn., 28, 23-29.

ESRI, 2009a. An Overview of Spatial Analyst, Environmental Systems Research Institute, Redlands, CA. Available online at: http://webhelp.esri.com/arcgisdesktop/9.3/index.cfm? TopicName $=$ An_overview_of_Spatial_Analyst.

ESRI, 2009b. An Overview of the Solar Radiation Tools, Environmental Systems Research Institute, Redlands, CA. Available online at: http://webhelp.esri.com/arcgisdesktop/ 9.3/index.cfm?TopicName = An_overview_of_the_Solar_ Radiation_tools
Fărcaş I. and Sorocovschi V., 1992. The climate of the Retezat Mountains. In: Popovici I. (ed.), The Retezat National Park, Ecological Studies, West Side Computers, Braşov, 13-20.

Fjellheim A., Raddum G.G., Vandvik V., Cogălniceanu D., Boggero A., Brancelj A., Galas J., Sporka F., Vidinova Y., Bitusik P., Dumnicka E., Gâldean N., Kownacki A., Krno I., Preda E., Rîşnoveanu G. and Stuchlik E., 2009. Diversity and distribution patterns of benthic invertebrates along alpine gradients. A study of remote European freshwater lakes. Adv. Limnol., 62, 159-176.

Fu P. and Rich P.M., 2002. A geometric solar radiation model with applications in agriculture and forestry. Comput. Electron. Agr., 37, 25-35.

Funk W.C., Blouin M.S., Corn P.S., Maxell B.A., Pilliod D.S., Amish S. and Allendorf F.W., 2005. Population structure of Columbia spotted frogs (Rana luteiventris) is strongly affected by the landscape. Mol. Ecol., 14, 483-496.

Glos J., Grafe U.T., Rödel M.O. and Linsenmair K.E., 2003. Geographic variation in $\mathrm{pH}$ tolerance of two populations of the European common frog, Rana temporaria. Copeia, 3, 650-656.

Grözinger F., Wertz A., Thein J., Feldhaar H. and Rödel M.O., 2012. Environmental factors fail to explain oviposition site use in the European common frog. To be published in J. Zool.

Harrison S. and Taylor A.D., 1997. Empirical evidence for metapopulation dynamics. In: Hanski I. and Gilpin M.E. (eds.), Metapopulation Biology: Ecology, Genetics, and Evolution, Academic Press, San Diego, CA, 27-42.

Jarvis A., Reuter H.I., Nelson A. and Guevara E., 2008. Holefilled seamless SRTM data V4, International Centre for Tropical Agriculture (CIAT). Available online at: http://srtm.csi.cgiar.org

Koining K.A., Schmidt R., Sommaruga-Wögrath S., Tessadri R. and Psenner R., 1998. Climate change as the primary cause for $\mathrm{pH}$ shifts in a high alpine lake. Water Air Soil Pollut., 104, 167-180.

Kovar R., Brabec M., Vita R. and Bocek R., 2009. Spring migration distances of some Central European amphibian species. Amphibia-Reptilia, 30, 367-378.

Kuzmin S., Tuniyev V.I.B., Beebee T., Andreone F., Nyström P., Anthony B., Schmidt B., Ogrodowczyk A., Ogielska M., Bosch J., Miaud C., Loman J., Cogălniceanu D., Kovács T. and Kiss I., 2009. Rana temporaria. IUCN 2011. IUCN Red List of Threatened Species. Version 2011.2

Lindgren B. and Laurila A., 2010. Are high-latitude individuals superior competitors? A test with Rana temporaria tadpoles. Evol. Ecol., 24, 115-131.

Loman J., 1999. Early metamorphosis in common frog Rana temporaria at risk of drying: an experimental demonstration. Amphibia-Reptilia, 20, 421-430.

Mazerolle M.J., 2009. AICcmodavg: model selection and multimodel inference based on (Q)AIC(c), version 1.06.

Merilä J., Laurila A., Timenes L.A., Rasanen K. and Pahkala M., 2000. Plasticity in age and size at metamorphosis in Rana temporaria - comparison of high and low latitude populations. Ecography, 23, 457-465.

Miaud C. and Merilä J., 2001. Local adaptation or environmental induction? Causes of population differentiation in alpine amphibians. Biota, 2, 31-50.

Miaud C., Guyetant R. and Elmberg J., 1999. Variations in lifehistory traits in the common frog Rana temporaria 
(Amphibia: Anura): a literature review and new data from the French Alps. J. Zool., 249, 61-73.

Miaud C., Guyetant R. and Faber H., 2000. Age, size, and growth of the alpine newt, Triturus alpestris (Urodela: Salamandridae) at high altitude and a review of life-history trait variation throughout its range. Herpetologica, 56, 135144.

Pişotă I., 1971. Lacurile glaciare din Carpaţii Meridionali. Studiu hidrologic. [Glacial Lakes from the Southern Carpathians. Hydrological Study]. Editura Academiei, Bucharest, Romania.

Plăiaşu R., Băncilă R.I., Samoilă C. and Cogălniceanu D., 2010. Factors influencing the breeding habitat use by amphibians in the alpine area of the Retezat National Park (Romania). Trav. Mus. Nat. d'Hist. Nat. "Gr. Antipa”, 53, 469-478.

Psenner R. and Schmidt R., 1992. Climate-driven pH control of remote alpine lakes and effects of acid deposition. Nature, 356, 781-783.

Pyke C.R. and Marty R.J., 2005. Cattle grazing mediates climate change impacts on ephemeral wetlands. Conserv. Biol., 19, 1619-1625.

R Development Core Team, 2009. R: A Language and Environment for Statistical Computing, R Foundation for Statistical Computing. Vienna. Available online at: http://www.R-project.org

Schmutzer A.C., Gray M.J., Burton E.C. and Miller D.L., 2008. Impacts of cattle on amphibian larvae and the aquatic environment. Freshwater Biol., 53, 2613-2625.

Schreiber W. and Sorocovschi V., 1992. The Retezat Mountains. Physico-geographic data. In: Popovici I. (ed.), The Retezat National Park. Ecological Studies, West Side Computers, Braşov, 8-12.
Sommer S. and Pearman P.B., 2003. Quantitative genetic analysis of larval life history traits in two alpine populations of Rana temporaria. Genetica, 118, 1-10.

Straskrabova V., Cogălniceanu D., Nedoma J., Parpală L., Postolache C., Tudorancea C., Vădineanu A., Vâlcu C. and Zinevici V., 2006. Bacteria and pelagic food webs in pristine mountain lakes (Retezat, Romania). Transylv. Rev. Syst. Ecol. Res., 3, 1-10.

Tattersall G.J. and Ultsch G.R., 2008. Physiological ecology of aquatic overwintering in Ranid frogs. Biol. Rev., 83, 119-140.

Urdea P., 2000. Munţii Retezat. Studiu Geomorfologic. [The Retezat Mountains. Geomorphological Study]. Editura Academiei Române, Bucharest, Romania.

Van Buskirk J., 2005. Local and landscape influence on amphibian occurrence and abundance. Ecology, 86, 19361947.

Veith M., Vences M., Vieites D.R., Nieto-Roman S. and Palanca A., 2002. Genetic differentiation and population structure within the Spanish common frogs (Rana temporaria complex: Ranidae, Amphibia). Folia Zool., 51, 307-318.

Vences M., Grossenbacher K., Puente M., Palanca A. and Vieites D.R., 2003. The Cambalès fairy tale: elevational limits of Rana temporaria (Amphibia: Ranidae) and other European amphibians revisited. Folia Zool., 52, 189-202.

Vieites D.R., Nieto-Román S., Barluenga M., Palanca A., Vences M. and Meyer A., 2004. Post-mating clutch piracy in an amphibian. Nature, 431, 305-308.

Wolfe A.P., Baron J.S. and Cornett R.J., 2001. Anthropogenic nitrogen deposition induces rapid ecological changes in alpine lakes of the Colorado Front Range (USA). J. Paleolimnol., 25, 1-7. 